\title{
A conspiracy of glioma and endothelial cells to invade the normal brain
}

\author{
Abdessamad Zerrouqi ${ }^{1}$ and Erwin G Van Meir ${ }^{1,2,3}$ \\ ${ }^{1}$ Laboratory of Molecular Neuro-Oncology, Department of Neurosurgery, Emory School of Medicine, Emory University, \\ Atlanta, GA, USA \\ 2 Departments of Hematology and Medical Oncology, Emory School of Medicine, Emory University, Atlanta, Georgia, USA \\ ${ }^{3}$ Winship Cancer Institute, Emory University, Atlanta, Georgia, USA \\ Correspondence to: Erwin G Van Meir, email: evanmei@emory.edu \\ Commentary on: Tie2/TEK modulates the interaction of glioma and brain tumor stem cells with endothelial cells and promotes an \\ invasive phenotype
}

Received: February 17, 2011, Accepted: February 17, 2011, Published: February 18, 2011

Copyright: @ Zerrouqi et al. This is an open-access article distributed under the terms of the Creative Commons Attribution License, which permits unrestricted use, distribution, and reproduction in any medium, provided the original author and source are credited.

Gliomas are the most common primary tumors of the central nervous system, accounting for the majority of adult primary brain tumors [1]. One of the major pathophysiological features of malignant human gliomas is their ability to diffusely and deeply invade into surrounding brain tissues [2-4]. The invasive phenotype is acquired early during glioma progression; even in low grade tumors, single or small groups of cells detach from the original site, attach to and remodel the extracellular matrix (ECM) during their migration, and penetrate and destroy adjacent brain structures [5]. The diffusely infiltrative nature of gliomas is believed to underlie tumor recurrence after surgery; therefore, understanding the mechanisms of glioma invasiveness and their response to therapy are very important.

To investigate these processes, initial work has focused on tumor-ECM interactions. The invasive process of glioma cells requires changes in the adhesive properties of the cells and expression of proteases. Neural cell adhesion molecules [6] and E-cadherin [7] are downregulated, while CD44 [8] and N-cadherin [7, $9,10]$ are upregulated. Attachment to ECM involves integrins such as $\beta 1$-integrin [11-13] and tenascin-C [14]. ECM remodeling is accomplished via the action of several classes of proteases including matrix metalloproteinases (MMPs), [2], ADAMs (a disintegrin and metalloproteinase), plasmin and cathepsins (2). Invasion also requires cytoskeletal rearrangements, formation of focal adhesions and lamellipodia involving Rho and Rac [15].

The human Angiopoietin / Tie system plays a crucial role in the remodeling of the tumor microenvironment that accompanies the angiogenic switch in tumors, in order to control endothelial cell survival and vascular maturation and thereby promoting tumor growth.

The Angiopoietin family includes four ligands (Angiopoietins-1, 2, 3 and 4). The best characterized are Ang1 and 2, while the role of Ang3 and Ang4 are less well known. These ligands bind to the Tie 1 and Tie 2 tyrosine kinase receptors. Tie2 is well studied and expressed by endothelial cells, hematopoietic cells and tumor cells, and binds both Ang-1 and Ang-2 with similar affinity. In contrast, Tie1 is an orphan receptor, exclusively expressed by endothelial cells (ECs) whose role is incompletely defined [16].

Ang-1, secreted by perivascular cells and pericytes, acts in a paracrine agonistic manner and induces endothelial Tie2 phosphorylation and subsequent vessel stabilization. Ang1 binding to Tie2 results in receptor dimerization, which stimulates autophosphorylation of the Tie2 kinase domain [17], and triggers survival signaling in resting ECs by activating PI3kinase/AKT [18]. The signaling through PI3kinase promotes Ang1induced cell survival, control of vascular permeability and regulates the capillary sprouting that occurs during normal and tumoral angiogenesis [19].

In contrast, Ang-2 acts as an antagonist of Ang-1mediated Tie2 activation. Autocrine production of Ang2 by endothelial cells serves as a rheostat to control the level of Tie2 phosphorylation by Ang1. Ang2 modulates the vascular remodeling occurring during angiogenesis in a cooperative manner with pro-angiogenic factors including vascular endothelial growth factor-A (VEGF-A) [20]. Ang2 dose-dependently inhibits Ang1-induced Tie2 phosphorylation, Akt activation, EC survival [21], and induces vessel destabilization and pericyte dropout at higher concentration. Ang-2 is strongly expressed in the vasculature of many tumors where it is believed to act synergistically with pro-angiogenic cytokines and promote 
tumor-associated angiogenesis and tumor progression. The elevation of expression of VEGF and Ang2 is believed to play a key role in the pseudopalisading necrosis and associated glomeruloid microvascular proliferation that are pathognomonic features of glioblastomas [22-24].

Although Tie2 was originally described as a specific receptor for endothelium, its expression has been reported in nonvascular normal and neoplastic tissues [12, 25, 26]. Tie2 was found expressed by hematopoietic stem cells [27], and in gastric [28], thyroid [29] and breast cancers [30]. The expression of Tie2 is particularly high in glioma as compared to normal brain tissue, and increases with the progression from low to high grade gliomas [12]. Tie2 activation can modify the adhesion properties of glioma cells by increasing their binding to ECM components such as collagen type I and IV through the induction of the expression of $\beta 1$-integrin [12], similar to observations in hematopoietic stem cells [27].

A new study by Liu et al [31] in the recent December issue of Oncotarget broadens our knowledge of glioma cell invasion to interactions with other cells in the tumor environment. They propose that Tie $2 /$ Ang1 promotes the invasion phenotype by modulating the interaction of glioma and brain tumor stem like cells (BTSC) with endothelial cells. This cooperation was evidenced when Tie2-positive tumor cells were co-injected with endothelial cells in brains of immunocompromised mice. The tumor cells migrated farther from the injection site, developed multifocal tumors surrounding vascular structures and tended to be more aggressive than Tie 2 negative-tumors. They determined that Ang1-mediated Tie2 activation in glioma cells and BTSCs enhances their adhesion to human umbilical vein endothelial cells in vitro. The mechanism underlying the latter effects involves the upregulation of $\beta 1$-integrin and N-cadherin (Fig.1). While VEGF may regulate endothelial cell-cell or cell-matrix interactions [32], they found Ang1/Tie2 mediated adhesion to be VEGF independent. Tie2 also increased the tumor cells' autonomous invasion capabilities in a $3 \mathrm{D}$ matrix, but unfortunately, the influence of endothelial cells was not proposed that heterotypic cell contact/communication between cancer cells and adjacent vascular cells can boost

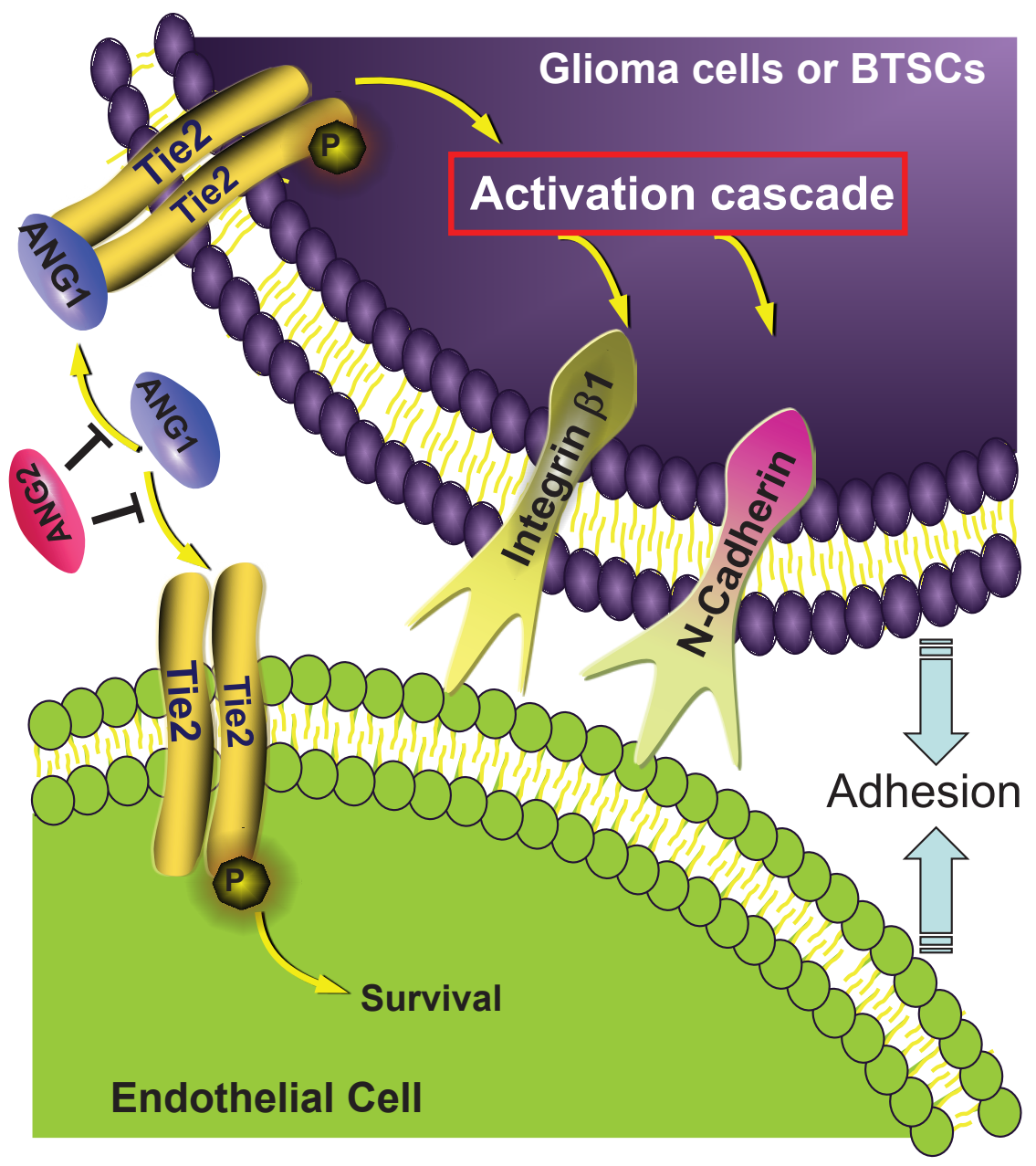

Fig 1: Tie2 activation enhances the interaction of glioma and brain tumor stem-like cells with endothelial cells and promotes their invasive phenotype. Angiopoietin1 (Ang1) present in the extracellular matrix activates Tie2 that is expressed by glioma and brain tumor stem-like cells (BTSC) and thereby upregulates $\beta 1$-integrin and N-cadherin. This upregulation increases cancer- endothelial cell interactions, which promote tumor cells to invade healthy brain tissue. Ang2 acts as antagonist of Ang1 and prevents Tie2 receptor activation. 
the tumor invasive phenotype and thereby malignancy. These findings provide new insights on how expression of Tie 2 on tumor cells is translated into a highly infiltrative phenotype in human gliomas.

The in vivo tumor phenomenon observed by Liu et al [31] is intriguing and raises further questions. How do tumor cells more efficiently invade normal brain tissue and establish tumor foci when they coexist with endothelial cells? Does this phenomenon require tumor cells to bind to and co-migrate with endothelial cells? Are endothelial cells providing paracrine pro-migratory or pro-survival signals for cancer stem-like cells? Do the endothelial cells participate in accelerating the formation of a vascular supply to the tumor? Clearly, the effect is Tie2-dependent, as it was not observed in parental tumor cells mixed with endothelial cells. A demonstration of this effect with brain endothelial cells and a careful analysis of their presence in clusters of migrating Tie-2- positive glioma cells and alteration of $\mathrm{N}$-cadherin and $\beta 1$-integrin should help answer this question and provide a link with the in vitro findings on adhesion.

What do these novel findings mean for therapy? Since this increase in malignancy of glioma cells is associated with Tie2 expression, the obvious strategy is to target the signaling emanating from Tie2 upon angiopoietin activation. A handful of drugs targeting Tie2 tyrosine kinase are under clinical evaluation (CEP-11981, CE-245677 and AMG-386). Another clinically relevant question is whether changes in the invasive phenotype seen in tumors of patients treated with anti-VEGF antibodies (Bevacizumab), are related to Tie2 upregulation and this VEGF-independent invasive mechanism. The results of the clinical trials conducted with these agents and a deeper mechanistic understanding of glioma-endothelial cell communication in invasion will significantly extend this knowledge to more effective clinical translation for the treatment of glioblastoma patients. We eagerly anticipate more to unfold in this interesting (com)plot.

\section{REFERENCES}

1. Van Meir EG, Hadjipanayis CG, Norden AD, Shu HK, Wen PY, Olson JJ. Exciting new advances in neuro-oncology: the avenue to a cure for malignant glioma. CA Cancer J Clin. 2010;60:166-93.

2. Bellail AC, Hunter SB, Brat DJ, Tan C, Van Meir EG. Microregional extracellular matrix heterogeneity in brain modulates glioma cell invasion. Int $\mathrm{J}$ Biochem Cell Biol. 2004;36:1046-69.

3. Visted T, Enger PO, Lund-Johansen M, Bjerkvig R. Mechanisms of tumor cell invasion and angiogenesis in the central nervous system. Front Biosci. 2003;8:e289-304.

4. Viapiano MS, Lawler SE. (2009). Glioma Invasion: Mechanisms and Therapeutic Challenges. In: CNS Cancer, Van Meir EG, ed. Humana Press, pp. 1219-52.
5. Nakada M, Nakada S, Demuth T, Tran NL, Hoelzinger DB, Berens ME. Molecular targets of glioma invasion. Cell Mol Life Sci. 2007;64:458-78.

6. Sasaki H, Yoshida K, Ikeda E, Asou H, Inaba M, Otani M, Kawase T. Expression of the neural cell adhesion molecule in astrocytic tumors: an inverse correlation with malignancy. Cancer. 1998;82:1921-31.

7. Cavallaro U, Christofori G. Cell adhesion and signalling by cadherins and Ig-CAMs in cancer. Nat Rev Cancer. 2004;4:118-32.

8. Ranuncolo SM, Ladeda V, Specterman S, Varela M, Lastiri J, Morandi A, Matos E, Bal de Kier Joffe E, Puricelli L, Pallotta MG. CD44 expression in human gliomas. J Surg Oncol. 2002;79:30-5; discussion 5-6.

9. Shinoura N, Paradies NE, Warnick RE, Chen H, Larson JJ, Tew JJ, Simon M, Lynch RA, Kanai Y, Hirohashi $\mathrm{S}$, et al. Expression of $\mathrm{N}$-cadherin and alpha-catenin in astrocytomas and glioblastomas. Br J Cancer. 1995;72:62733.

10. Asano K, Duntsch CD, Zhou Q, Weimar JD, Bordelon D, Robertson JH, Pourmotabbed T. Correlation of N-cadherin expression in high grade gliomas with tissue invasion. $\mathrm{J}$ Neurooncol. 2004;70:3-15.

11. Giese A, Rief MD, Loo MA, Berens ME. Determinants of human astrocytoma migration. Cancer Res. 1994;54:3897904.

12. Lee $\mathrm{OH}, \mathrm{Xu}$ J, Fueyo J, Fuller GN, Aldape KD, Alonso MM, Piao Y, Liu TJ, Lang FF, Bekele BN, GomezManzano C. Expression of the receptor tyrosine kinase Tie2 in neoplastic glial cells is associated with integrin beta1-dependent adhesion to the extracellular matrix. Mol Cancer Res. 2006;4:915-26.

13. D'Abaco GM, Kaye AH. Integrins: molecular determinants of glioma invasion. J Clin Neurosci. 2007;14:1041-8.

14. Mahesparan R, Read TA, Lund-Johansen M, Skaftnesmo $\mathrm{KO}$, Bjerkvig R, Engebraaten O. Expression of extracellular matrix components in a highly infiltrative in vivo glioma model. Acta Neuropathol. 2003;105:49-57.

15. Chan AY, Coniglio SJ, Chuang YY, Michaelson D, Knaus UG, Philips MR, Symons M. Roles of the Rac1 and Rac3 GTPases in human tumor cell invasion. Oncogene. 2005;24:7821-9.

16. Thomas M, Augustin HG. The role of the Angiopoietins in vascular morphogenesis. Angiogenesis. 2009;12:125-37.

17. Maisonpierre PC, Suri C, Jones PF, Bartunkova S, Wiegand SJ, Radziejewski C, Compton D, McClain J, Aldrich TH, Papadopoulos N, Daly TJ, Davis S, Sato TN, Yancopoulos GD. Angiopoietin-2, a natural antagonist for Tie2 that disrupts in vivo angiogenesis. Science. 1997;277:55-60.

18. Saharinen P, Eklund L, Miettinen J, Wirkkala R, Anisimov A, Winderlich M, Nottebaum A, Vestweber D, Deutsch U, Koh GY, Olsen BR, Alitalo K. Angiopoietins assemble distinct Tie2 signalling complexes in endothelial cell-cell and cell-matrix contacts. Nat Cell Biol. 2008;10:527-37. 
19. Wong AL, Haroon ZA, Werner S, Dewhirst MW, Greenberg CS, Peters KG. Tie2 expression and phosphorylation in angiogenic and quiescent adult tissues. Circ Res. 1997;81:567-74.

20. Peters KG, Kontos CD, Lin PC, Wong AL, Rao P, Huang L, Dewhirst MW, Sankar S. Functional significance of Tie2 signaling in the adult vasculature. Recent Prog Horm Res. 2004;59:51-71.

21. Yuan HT, Khankin EV, Karumanchi SA, Parikh SM. Angiopoietin 2 is a partial agonist/antagonist of Tie2 signaling in the endothelium. Mol Cell Biol. 2009;29:201122.

22. Brat DJ, Van Meir EG. Vaso-occlusive and prothrombotic mechanisms associated with tumor hypoxia, necrosis, and accelerated growth in glioblastoma. Lab Invest. 2004;84:397-405.

23. Tohma Y, Gratas C, Van Meir EG, Desbaillets I, Tenan M, Tachibana O, Kleihues P, Ohgaki H. Necrogenesis and Fas/APO-1 (CD95) expression in primary (de novo) and secondary glioblastomas. J Neuropathol Exp Neurol. 1998;57:239-45.

24. Brat DJ, Castellano-Sanchez A, Kaur B, Van Meir EG. Genetic and biologic progression in astrocytomas and their relation to angiogenic dysregulation. Adv Anat Pathol. 2002;9:24-36.

25. Iwama A, Hamaguchi I, Hashiyama M, Murayama Y, Yasunaga K, Suda T. Molecular cloning and characterization of mouse TIE and TEK receptor tyrosine kinase genes and their expression in hematopoietic stem cells. Biochem Biophys Res Commun. 1993;195:301-9.

26. Sato TN, Qin Y, Kozak CA, Audus KL. Tie-1 and tie-2 define another class of putative receptor tyrosine kinase genes expressed in early embryonic vascular system. Proc Natl Acad Sci U S A. 1993;90:9355-8.

27. Arai F, Hirao A, Ohmura M, Sato H, Matsuoka S, Takubo K, Ito K, Koh GY, Suda T. Tie2/angiopoietin-1 signaling regulates hematopoietic stem cell quiescence in the bone marrow niche. Cell. 2004;118:149-61.

28. Wang J, Wu K, Zhang D, Tang H, Xie H, Hong L, Pan Y, Lan M, Hu S, Ning X, Fan D. Expressions and clinical significances of angiopoietin-1, -2 and Tie2 in human gastric cancer. Biochem Biophys Res Commun. 2005;337:386-93.

29. Mitsutake N, Namba H, Takahara K, Ishigaki K, Ishigaki J, Ayabe H, Yamashita S. Tie-2 and angiopoietin-1 expression in human thyroid tumors. Thyroid. 2002;12:95-9.

30. Dales JP, Garcia S, Bonnier P, Duffaud F, MeunierCarpentier S, Andrac-Meyer L, Lavaut MN, Allasia C, Charpin C. Tie2/Tek expression in breast carcinoma: correlations of immunohistochemical assays and longterm follow-up in a series of 909 patients. Int J Oncol. 2003;22:391-7.

31. Liu D, Martin V, Fueyo J, Lee O-H, Xu J, Cortes-Santiago N, Alonso MM, Aldape K, Colman H, Gomez-Manzano C. Tie2/TEK Modulates the Interaction of Glioma and Brain
Tumor Stem Cells with Endothelial Cells and Promotes an Invasive Phenotype. Oncotarget. 2010;1:700-9.

32. Fong GH, Rossant J, Gertsenstein M, Breitman ML. Role of the Flt-1 receptor tyrosine kinase in regulating the assembly of vascular endothelium. Nature. 1995;376:66-70. 